\title{
A COST OF ILLNESS STUDY OF TYPE 2 DIABETES MELLITUS IN MANGALORE, KARNATAKA, INDIA
}

\author{
USHA ADIGA ${ }^{1}$, SACHIDANANDA ADIGA ${ }^{2 *}$ \\ ${ }^{1}$ Department of Biochemistry, K. S. Hegde Medical Academy, Nitte-Deemed to be University, Mangalore, Karnataka, India. ${ }^{2}$ Department of \\ Pharmacology, K. S. Hegde Medical Academy, Nitte-Deemed to be University, Mangalore, Karnataka, India. Email: ushachidu@yahoo.com
}

Received: 26 May 2018, Revised and Accepted: 02 July 2018

\section{ABSTRACT}

Objective: The aim of the study was to study the cost of illness of uncomplicated and complicated type 2 diabetes mellitus.

Methods: The non-interventional retrospective study was carried out in K.S. Hegde Medical Academy. Annual laboratory costs, pharmacy cost, consultation charges, hospital bed charges, and surgical/intervention costs of 340 diabetic patients were obtained from the medical record section of the hospital. Patients were divided into six groups, uncomplicated, diabetic retinopathy (DR), nephropathy, neuropathy, diabetic foot (DF), and those with ischemic heart disease (IHD) and different costs were compared. Correlation of costs with duration of the study and glycemic control were studied.

Results: Uncomplicated patients had significantly lower costs $(\mathrm{p}<0.0001)$ compared to other groups. Patients with IHD had highest expenses $(\mathrm{p}<0.0001)$, followed by diabetic nephropathy (DN) and DF $(\mathrm{p}<0.0001)$. Cost incurred in diabetic neuropathy (DNeu) was almost the double compared to uncomplicated group, but annual medical cost (AMC) was minimum among other diabetic complications. DR had higher expenses compared to DNeu. The similar pattern of distribution was observed in other individual costs. A positive correlation was observed between the costs incurred and duration of diabetes, a negative correlation between the glycemic status and cost incurred. Cost incurred was double when compared to that of previous decade.

Conclusion: The total AMC is significantly higher in complicated diabetic patients as compared to those without complications. Diabetic patients with IHD had the highest expenses, followed by DN, DF, DR, and DNeu which was least expensive.

Keywords: Cost of illness, Direct medical cost, Complications, Type 2 diabetes mellitus.

(C) 2018 The Authors. Published by Innovare Academic Sciences Pvt Ltd. This is an open access article under the CC BY license (http://creativecommons. org/licenses/by/4. 0/) DOI: http://dx.doi.org/10.22159/ajpcr.2018.v11i11.27558

\section{INTRODUCTION}

Diabetes mellitus (DM) is a disease that has significant economic impact on both for the patient and the health-care provider due to its chronicity and multiorgan Involment which results in frequent visit and admission to health facilities. High prevalence and higher rate of Complications endanger substantial negative implication on the economies. Costs involved in the management of diabetes can be classified into direct and indirect or intangible costs. Direct cost includes hospital services, including consultation charges, laboratory tests, and the daily management of DM, which includes the availability of products such as insulin, syringes, oral hypoglycemic agents, and blood glucose testing equipment which are known as pharmacy costs. Due to coexisting complications, patients may have hospital admissions and undergo various interventions/surgeries which enormously increase the direct costs. Transportation cost is known as direct non-medical cost. Costs range from relatively low-cost items, such as primary-care consultations and hospital outpatient episodes, to very high-cost items, such as long hospital inpatient stays for the treatment of complications [1]. Indirect cost includes loss of productivity due to sickness, absenteeism, disability, premature retirement, and premature mortality of the patients.

Due to these expenses, DM poses a great economic burden on the society which is of great concern.

Shobhana et al. reported a total annual cost of INR 4510 in a public sector hospital at Chennai in 1999, whereas the same author reports an annual cost of INR 15,596 in inpatients and INR 8578 in outpatients in an another study [2,3]. A cross-sectional study by Rao et al. reports cost for hospitalization INR 5925 in 2004 [4]. In 2005, three study reports are available to the best of our knowledge, among which cohort study in Northern India by Grover et al. reported a total cost of INR 4966.2 over 6 months in patients with diabetes inclusive of consultations, investigations, nursing, and infrastructure. He also reported an indirect cost due to loss of wages was INR 2086.74, which also included drugs, food, and travel. [5]. However, small sample size was the limitation of the study. Kumar et al. reported a total direct cost of INR 6212.4, inclusive of tests, drugs, monitoring, etc., in his cohort study conducted in Delhi [6]. Ramachandran et al., in a cross-sectional study covering seven states in India, reported an annual direct cost of INR 8130 which included drugs, tests, hospitalization, surgery, and consultation [7]. A regional cohort study by Shivprakash et al. suggests a consultation charge of INR 363 [8]. In our previous report, we found that annual cost per diabetic person was INR 10,584, 19,326, and 25,960 for uncomplicated, complicated but not admitted, and complicated and admitted diabetics, respectively, in 2009 [9]. A study by Kumpatla et al. reports an annual expenditure of INR 4493 and 15280 with and without complications, respectively, in Chennai in 2009 [10]. A cross-sectional study from Maharashtra, by Kuchake et al. in 2010, reported a consultation cost of INR 116.85 and a Punjab-based study by Joshi et al. reported a consultation cost of INR $166[11,12]$.

In 2012, Hanamkonda-based cohort study by Akari et al. reported an annual direct cost of USD 314.15 in complicated diabetic patients and USD 29.91 in uncomplicated diabetic patients [13]. In a South Indiabased randomized control trial by Abdi et al. reported a drug cost of USD 13.42 [14]. 
There are various studies which tried to evaluate the economic burden due to DM, but each one of them has its own limitations due to lack of standardization of the methods used, improper documentation of data, lack of follow-up, etc. This study is an attempt to evaluate the economic burden of diabetes in a coastal district of Karnataka, India.

\section{Objectives}

To assess the annual medical cost (AMC) and consultation charges (directmedical costs) in uncomplicated hospitalized patients and annual health-care costs due to type 2 diabetes patients who are hospitalized due to various complications in coastal district of Karnataka, India.

Primary objectives are to:

1. Compare direct costs such as, AMC, annual laboratory cost (ALC), annual pharmacy cost (APC), annual consultation cost (ACC), annual hospital bed costs (AHBC), and annual surgical/intervention cost (ASC) in Type 2 DM (T2DM) patients, with and without complications

2. Compare AMC and other costs in diabetic patients with various complications

3. Find out correlation between cost incurred to the duration of diabetes

4. Find relationship between glycemic status, complications of DM, and cost incurred.

\section{METHODS}

\section{Study design}

Type of study

This study was a non-interventional retrospective study.

\section{Study population}

T2DM patients attending Justice K.S. Hegde Hospital, Nitte University, Mangalore, for at least 1 year.

\section{Inclusion criteria}

A total of 340 T2DM patients, 18-55 years of either gender will be included in the study. Patients attending the hospital services, with and without complications were included in the study. Patients with T2DM were identified by the American Diabetic Association guidelines 2017. Diabetes complications and comorbidities were identified using ICD codes. Systematic sampling was conducted for 340 identified DM patients after obtaining permission from the Medical superintendent and Institutional Ethics Committee.

\section{Exclusion criteria}

Type 1 diabetic patients, gestational diabetes, and those with any other associated illnesses, other than diabetic complications, like liver disorders, etc., were excluded from the study.

\section{Study period}

Data were collected from the medical records of diabetic patients who obtained treatment between July 1, 2016 and June 31, 2017.

\section{DATA COLLECTION}

The non-interventional retrospective study was conducted in a multispecialty teaching hospital attached to K.S. Hegde Medical Academy, Nitte University, Mangalore. It caters tertiary health-care service to the coastal district of Karnataka state, India. The data of patients such as age, gender, duration of illness, complications of diabetes, number of hospital visits per annum for consultation and admission, glycated hemoglobin levels, AMC like APC, ACC, ALC, AHBC, and ASC of patients who have been receiving regular treatment for T2DM from July 2016 to June 2017 were collected from the hospital medical record department. Patients were classified into six groups, i.e., patients with no complications (uncomplicated cystitis) - Group I, patients with diabetic complication who were hospitalized during 1 year with different complications like diabetic retinopathy (DR) - Group II, diabetic nephropathy (DN) - Group III, diabetic foot (DF) - Group IV, diabetic neuropathy (DNeu) - Group V, and ischemic heart disease/ coronary vascular diseases (IHD) - Group VI. The AHBC, ALC, APC, ACC, ASC, and total annual cost medical cost (AMC) during hospitalization were calculated separately for each group. Data were collected from the hospital medical record section.

All costs were reported in INR. Data were collected from the Medical Record Department of Justice K.S. Hegde Medical Hospital, where patient records were fully computerized as per ICD classification.

\section{Data analysis and interpretation}

The data collected was scrutinized and coded before entering into the computer. The data were analyzed using the software SPSS version 16. The entered data was verified and checked for data errors during coding and data entry.

\section{Statistical analysis}

Descriptive statistics was used for calculating mean, standard error of mean, percentage, and median. Kruskal-Wallis test followed by post hoc test, and Dunn's test was used to compare median costs between the groups as well as to compare costs in different groups based on duration of illness as well as complications. Spearman's correlation test was used to find the correlation between duration of illness and direct medical cost as well as glycemic status and medical cost.

\section{RESULTS}

The patient characteristics were depicted in the Table 1. Total direct mean, median medical cost and percentage costs depicted in Table 2 and Fig. 1. Comparison of mean and median costs in different groups are depicted in Tables 3 and 4. Post hoc test results depicting comparison of different groups in individual cost are depicted in Tables 5-10. Percentage contributions of these costs to AMC in Groups I-VI are depicted in Figs. 2-7.

A very highly significant differences $(\mathrm{p}<0.0001)$ in AMC, ALC, APC, ACC, $\mathrm{AHBC}$, and ASC between all the groups (Table 2).

Uncomplicated patients (Gp I) had significantly lower costs $(\mathrm{p}<0.0001)$ compared to other groups. Patients with IHD (Gp VI) had highest expenses ( $\mathrm{p}<0.0001)$, followed by DN (Gp III) and DF (Gp II) $(\mathrm{p}<0.0001)$. Cost incurred in DNeu (Gp V) was almost the double compared to uncomplicated group, but AMC was minimum among other diabetic complications. DR (Gp II) had higher expenses compared to DNeu (Gp V) (Table 4). The similar pattern of distribution was observed in other individual costs.

When we consider total direct medical cost, cost due to surgery/ intervention contributed to $65 \%$, laboratory charges $14 \%$, pharmacy and medications $12 \%$, bed charges due to hospital admissions $6 \%$, and consultation charges 3\% (Fig. 4).

On analyzing different costs in all the six groups, it was found that surgical/interventional costs contribute to 59\%-69\% of total direct medical costs, ALC to $12 \%-19 \%$, APC made up to $9 \%-15 \%$, ACC contributed to $3 \%-5 \%$, and AHBC accounted for $4 \%-6 \%$ of annual direct medical cost (AMC) (Figs. 2-7).

A positive correlation was observed between duration of complications and cost incurred $(\mathrm{r}=0.743, \mathrm{p}<0.001)$. There was a negative correlation between the glycemic status and cost incurred $(r=-0.604, p<0.001)$

\section{POST HOC TEST RESULTS}

Depicted in Tables 5-10

\section{DISCUSSION}

A very highly statistically significant differences $(p<0.0001)$ were observed in AMC, ALC, APC, ACC, AHBC, and ASC between all the groups (Table 2). Uncomplicated patients (Group I) had significantly lower costs $(\mathrm{p}<0.0001)$ compared to other groups. Patients with IHD 
(Group VI) had highest expenses ( $\mathrm{p}<0.0001$ ), followed by DN (Group III) and DF (Group II) $(\mathrm{p}<0.0001)$. Cost incurred in DNeu (Group V) was almost the double compared to uncomplicated group, but AMC was minimum among other diabetic complications. DR (Gp II) had higher expenses compared to DNeu (Group V) (Table 4). The similar pattern of distribution was observed in other individual costs.

It is evident from our study that direct health-care costs for treating diabetes and its complications are on the rise. The study revealed that the average cost of treating and managing diabetes-related IHD complications (Group VI) was the highest among all other complications. AMC was 7.2 times higher as compared to that in uncomplicated Group I. This increase in AMC is due to corresponding rise in laboratory charges (5.4 times), pharmacy charges (9.4 times), consultation charges (3.1 times), and hospital bed charges (4 times) due to probable increase in frequency and duration of admissions, higher surgical/intervention charges ( 7.4 times).

The maximum contribution is from medical appointments, tests, outpatient catheterization procedures, medications in use, and transport of the patient to the hospital, etc. In addition to hypoglycemic drugs, cardiologists prescriptions might contribute significantly to APC. We assumed that the drugs were purchased by the patients at pharmacies using their own resources without government subsidies and were taken with $100 \%$ treatment adherence. Additional laboratory tests to monitor cardiac functions and lipid profiles contributed to ALC. Cardiac and imaging tests included were myocardial scintigraphy (stress and resting), Echocardiography (stress and resting) exercise test, Holter, ambulatory blood pressure monitoring (ABPM), chest X-ray, carotid and vertebral Doppler echocardiography, venous color Doppler

Table 1: Demographic profile with glycemic parameters

\begin{tabular}{ll}
\hline Characteristics & Patient characteristics \\
\hline Gender & Male:Female $-60: 40$ \\
Mean age in years & $58.96 \pm 2.56$ \\
Duration of disease in years & $8.41 \pm 1.09$ \\
Hb1Ac (\%) & $7.69 \pm 0.11$ \\
\hline
\end{tabular}

Hb1Ac: Glycated hemoglobin

Table 2: Annual mean and median costs in T2DM

\begin{tabular}{lll}
\hline Parameters & Costs in INR (Mean \pm SEM) & Median \\
\hline AMC & $31500 \pm 1841.94$ & 17587.5 \\
ALC & $5874.23 \pm 325.4$ & 4118.9 \\
APC & $4772.42 \pm 367.75$ & 2399.9 \\
ACC & $1239.46 \pm 92.059$ & 949.55 \\
AHBC & $2246.49 \pm 155.699$ & 1147.55 \\
ASC & $26500 \pm 1605.65$ & 14629 \\
ATC & $1800 \pm 145.1$ & 1750 \\
\hline
\end{tabular}

T2DM: Type 2 diabetes mellitus, ATC: Annual transportation cost,

SEM: Standard error of mean, AMC: Annual medical cost, ALC: Annual

laboratory cost, APC: Annual pharmacy cost, ACC: Annual consultation cost, AHBC: Annual hospital bed costs, ASC: Annual surgical cost echocardiography, and chest tomography make major contribution to investigations. Hospital treatment consists of hospitalization days, Intensive Care Unit days, laboratory and diagnostic tests, angioplasty procedures with or without stent implantation, cardiac catheterization, and coronary artery bypass surgery performed during hospitalization made a huge contribution to ASC or intervention costs. Our results are supported by a recent Brazilian study by Schlatter et al., which showed that the direct costs of longitudinal IHD treatment were high and were primarily driven by chronic pharmacological treatment and days of hospitalization and interventions [15].

DN (Group III) was the second highest expensive complication of diabetes. AMC, ALC, APC, ACC, AHBC, and ASC were higher by 4.6, 3.3, $5.9,3.4,2.7$, and 4.6 times, respectively, compared to uncomplicated group. Higher cost incurred might be due to frequent investigations, consultations, and drugs. A recent study by Jose et al., focused on pharmacoeconomic aspects of DN from India, reported that monthly cost of dialysis contributed most (37\%) to the total cost in DN patients [16]. An earlier study from India reported that cost per dialysis in India ranged from INR 150 in government hospitals to INR 2000 in private hospitals [17]. In most of the private hospitals, the average cost of dialysis per patient per month was INR 12,000 and the yearly cost is INR 140,000 equivalent of USD 3000, and this is in sharp contrast to the annual cost of USD 60,000 in the United States and the United Kingdom. In the study by Jose et al., monthly average cost of dialysis per patient was INR 9060 [16]. The patients on an average underwent eight dialysis sessions per month in the study which was comparable with a study by Satyavani et al. done in a South Indian state [18]. This was not affordable to many patients as around $89 \%$ belonged to lower to middle-class socioeconomic strata in the study [16]. In a study by Satyavani et al., the cost for a person on hemodialysis was 4 times higher than for persons with chronic kidney disease (CKD) only (INR 61,170 vs. 12,664 ) [18]. A study by O'Brien et al. in Canada showed that early stage complications (e.g., microalbuminuria: USD 62 event cost; USD 10 state cost) had relatively low financial burden compared to more costly advanced stages (e.g., end-stage renal disease [ESRD], USD 63,045 state cost) [19]. Kidney transplantation remains the most cost-effective treatment for ESRD, offering considerable savings and improvement in the quality of life in these patientsas shown in a study by Satyavani et al. $[18,20]$. The total median cost of treatment of diabetic patients with ESRD was very high (on average INR 500,000) compared with transplant patient (INR 345,000) over a period of 2 years, whereas the average cost of treatment of diabetes with and without CKD was INR 100,000 and INR 30,000, respectively [21]. Strict glycemic and blood pressure control can reduce the incidence and slow the progression of DN [22]. Improvement in diabetes control, early diagnosis of DN, and treatment has the potential to reduce the direct cost involved in treatment of DN [21].

Our results are supported by the study by Kumpatla et al. who reported that total expenditure for treating renal, cardiovascular, and retinal complications was more or less similar among type 2 diabetic patients [10]. Satyavani et al. studied the direct cost of treating CKD in type 2 wdiabetic patients in India. The authors assessed the

Table 3: Mean costs incurred in uncomplicated and complicated DM

\begin{tabular}{lllllll}
\hline Costs in INR & $\begin{array}{l}\text { UC (I) } \\
(\mathbf{n = 1 1 7})\end{array}$ & $\begin{array}{l}\text { DR (II) } \\
(\mathbf{n = 3 2})\end{array}$ & $\begin{array}{l}\text { DN (III) } \\
\mathbf{( n = 4 1 )}\end{array}$ & $\begin{array}{l}\text { DF (IV) } \\
(\mathbf{n = 2 5})\end{array}$ & $\begin{array}{l}\text { DNeu (V) } \\
(\mathbf{n = 5 4 )}\end{array}$ & $\begin{array}{l}\text { IHD (VI) } \\
(\mathbf{n = 7 1 )}\end{array}$ \\
\hline AMC & $14230 \pm 1564.6$ & $23643 \pm 3223.4$ & $39374 \pm 4141.1$ & $39520 \pm 5010.1$ & $25021 \pm 3802.2$ & $61769 \pm 5560.6$ \\
ALC & $3369.3 \pm 307.3$ & $6296.9 \pm 1086.3$ & $7032.1 \pm 1081.1$ & $7537.2 \pm 1293.6$ & $5221.8 \pm 844.02$ & $9601.9 \pm 780.91$ \\
APC & $1651.3 \pm 259.77$ & $4013.3 \pm 676.4$ & $64333.6 \pm 1119.5$ & $8884.3 \pm 2331.7$ & $3893.8 \pm 685.5$ & $8328.8 \pm 912.5$ \\
ACC & $826.5 \pm 78.7$ & $1686.9 \pm 485.5$ & $1767.4 \pm 248$ & $1752.6 \pm 224.9$ & $1483 \pm 278.1$ & $2799.1 \pm 333.25$ \\
AHBC & $1150.6 \pm 154.54$ & $1631 \pm 522.44$ & $1883.9 \pm 296.51$ & $2692 \pm 685.29$ & $1354.2 \pm 220.46$ & $3274.2 \pm 483.38$ \\
ASC & $11652 \pm 136.21$ & $19900 \pm 2764.9$ & $28237 \pm 2865.1$ & $37189 \pm 4909.2$ & $21437 \pm 3429.9$ & $53724 \pm 4910.2$ \\
\hline
\end{tabular}

AMC: Annual medical cost, ALC: Annual laboratory cost, APC: Annual pharmacy cost, ACC: Annual consultation cost, AHBC: Annual hospital bed costs, ASC: Annual surgical cost, DM: Diabetes mellitus, UC: Uncomplicated cystitis, DR: Diabetic retinopathy, DN: Diabetic nephropathy, DF: Diabetic foot, DNeu: Diabetic neuropathy, IHD: Ischemic heart disease 


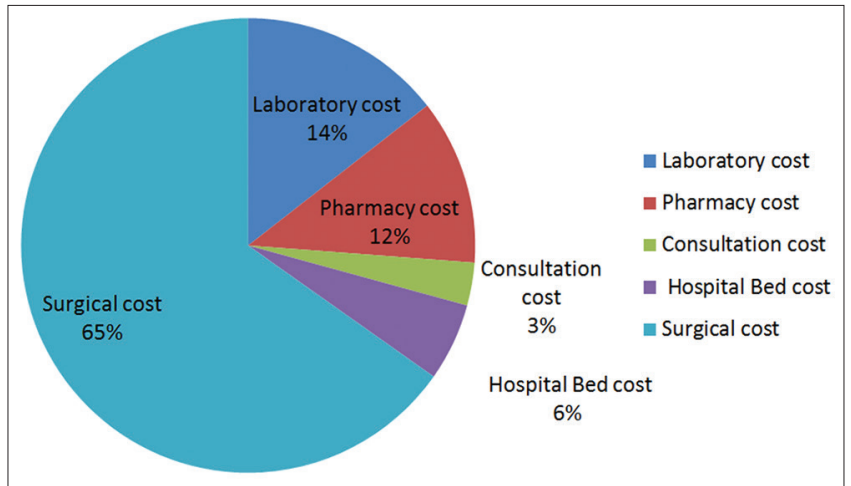

Fig. 1: Percentage distribution of medical costs of type 2 diabetes mellitus patients

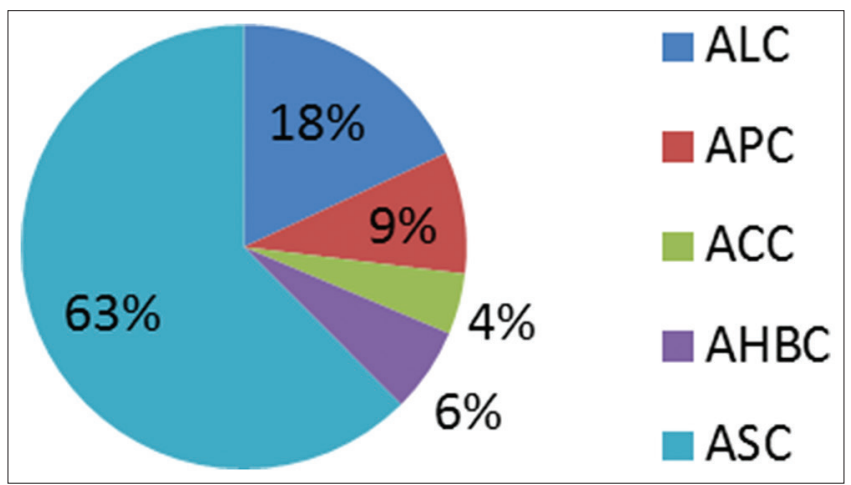

Fig. 2: Percentage of various costs in uncomplicated type 2 diabetes mellitus

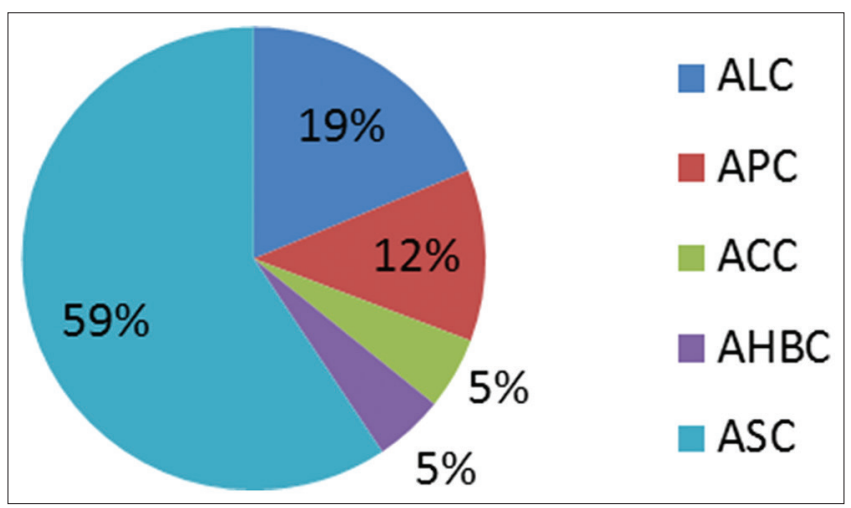

Fig. 3: Percentage of various costs in diabetic retinopathy

comparative cost of treatment of diabetic patients without CKD, those with Stage 1-4 CKD, who needs dialysis, and those with kidney transplantation [18]. They determined cost of treatment at two levels: Cost of hospitalization and total cost of treatment over the previous 2 years taking into account costs of hospitalization, consultation, medication, laboratory tests, dialysis treatment, transplantation surgery, and transportation. Ramachandran and Jha demonstrated that even kidney transplantation, the most cost-effective form of renal replacement therapy, in a public sector hospital can have catastrophic financial consequences pushing the majority of families into severe poverty [23].

DKD is preventable. There is substantial evidence that early and effective therapeutic intervention in type 2 diabetes can prevent DKD and retard the progression of established DKD.

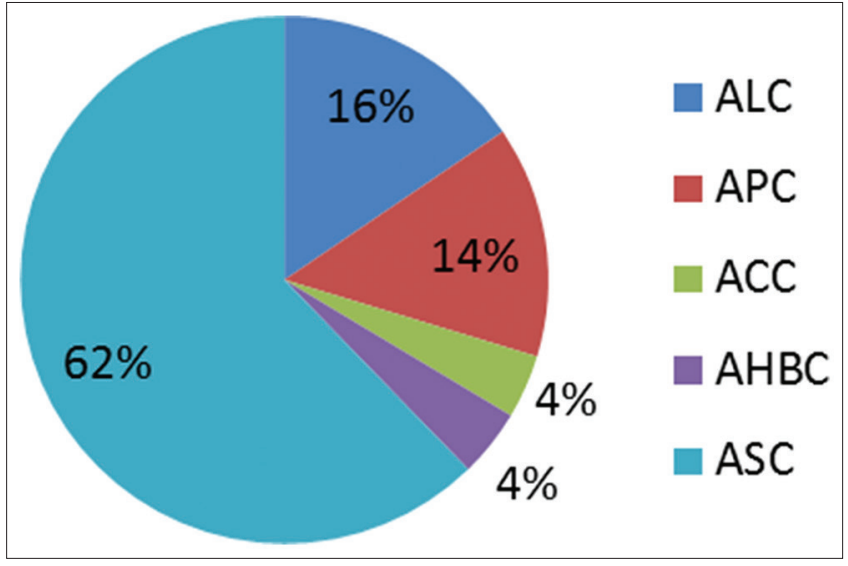

Fig. 4: Percentage of various costs in diabetic nephropathy

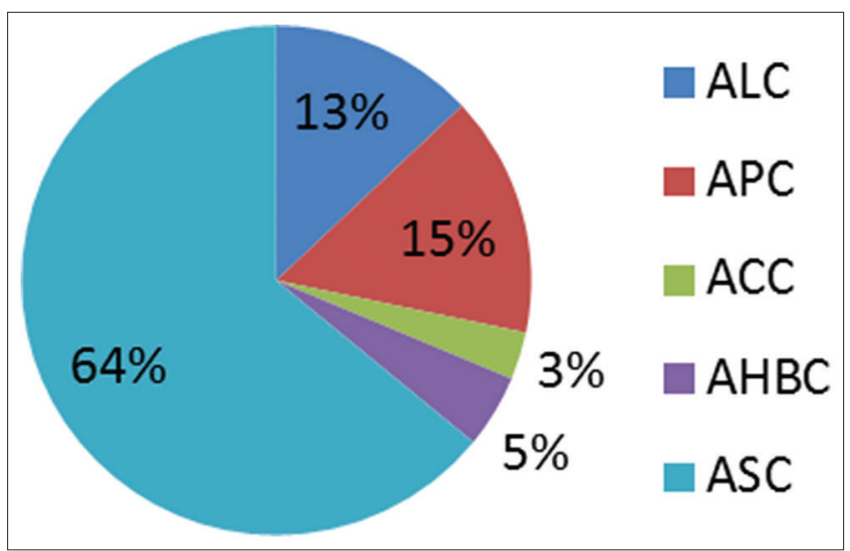

Fig. 5: Percentage of various costs in Douglas fur

DF (Group IV) was the next costliest complication. AMC, ALC, APC, ACC, AHBC, and ASC were higher by 4, 3.5, 6.1, 3.6, 2.8, and 4.8 times compared to uncomplicated group.

Some studies have shown $15 \%$ of diabetic patients will be suffering from DF ulcer during their lifetime [24]. DF ulcer is the most general cause of hospitalization in diabetic patients [25]. Lower extremity amputation is associated with prolonged hospitalization and rehabilitation and also required home care and social support which contribute to the economic burden [26]. It should be considered that the burden of DFrelated neuropathy is two folds than the burden of DR or nephropathy currently.

$85 \%$ of DF amputations are preventable with appropriate care and education. Ideal management for prevention and treatment of DF is as follow: Regular perception of foot, determine at-risk foot, education to patient and health staff, appropriate foot coverage, and early treatment of foot problems [27].

DR (Group II) was in fourth place to contribute to the health-care cost among the complications of DM. AMC, ALC, APC, ACC, AHBC, and ASC were $2.3,2,3.4,2.4,1.4$, and 2.3 times, respectively, higher compared to uncomplicated group. The increased cost could be attributed to screening, retinography, treatment costs, antivascular endothelial growth factor drugs, etc. There are hardly many studies done in this area in Indian settings. Average health-care costs increase considerably with the severity of retinopathy, which suggests that preventing progression of DR may lower health-care cost. 
Table 4: Median costs incurred in uncomplicated and complicated DM

\begin{tabular}{|c|c|c|c|c|c|c|c|}
\hline $\begin{array}{l}\text { Costs in } \\
\text { INR }\end{array}$ & $\begin{array}{l}\text { UC (I) } \\
(n=117)\end{array}$ & $\begin{array}{l}\text { DR (II) } \\
(n=32)\end{array}$ & $\begin{array}{l}\text { DN (III) } \\
(n=41)\end{array}$ & $\begin{array}{l}\text { DF (IV) } \\
(n=25)\end{array}$ & $\begin{array}{l}\text { DNeu (V) } \\
(n=54)\end{array}$ & $\begin{array}{l}\text { IHD (VI) } \\
(n=71)\end{array}$ & $p$ value \\
\hline AMC & 7750 & 17587.5 & 35875 & 30980 & 15237.5 & 55450 & $<0.0001$ \\
\hline ALC & 1919.8 & 3758.5 & 6405 & 6695 & 3016.05 & 10462.3 & $<0.0001$ \\
\hline APC & 936.5 & 3161.9 & 5540 & 5758 & 2418.65 & 8801.6 & $<0.0001$ \\
\hline ACC & 490 & 1154.8 & 1667.2 & 1765 & 915.5 & 1535 & $<0.0001$ \\
\hline AHBC & 552 & 784.6 & 1514.4 & 1569 & 614.4 & 2183.9 & $<0.001$ \\
\hline ASC & 6631 & 14936.4 & 30402.5 & 31631 & 12743.65 & 48860 & $<0.0001$ \\
\hline
\end{tabular}

DM: Diabetes mellitus, UC: Uncomplicated cystitis, DR: Diabetic retinopathy, DN: Diabetic nephropathy, DF: Diabetic foot, DNeu: Diabetic neuropathy, IHD: Ischemic heart disease, AMC: Annual medical cost, ALC: Annual laboratory cost, APC: Annual pharmacy cost, ACC: Annual consultation cost, AHBC: Annual hospital bed costs, ASC: Annual surgical cost

Table 5: Comparison of AMC in different groups

\begin{tabular}{ll}
\hline Groups & p value \\
\hline I vs. III & $<0.0001$ \\
I vs. IV & 0.001 \\
I vs. VI & $<0.0001$ \\
II vs. VI & $<0.0001$ \\
III vs. VI & 0.001 \\
IV vs. VI & 0.014 \\
V vs. VI & $<0.0001$ \\
\hline
\end{tabular}

Table 6: Comparison of ALC in different groups

\begin{tabular}{ll}
\hline Groups & p value \\
\hline I vs. III & 0.003 \\
I vs. IV & 0.013 \\
I vs. VI & $<0.0001$ \\
V vs. VI & $<0.0001$ \\
\hline ALC: Annual laboratory cost &
\end{tabular}

Table 7: Comparison of APC in different groups

\begin{tabular}{ll}
\hline Groups & p value \\
\hline I vs. III & $<0.0001$ \\
I vs. IV & $<0.0001$ \\
I vs. VI & $<0.0001$ \\
II vs. IV & 0.028 \\
II vs. VI & 0.008 \\
IV vs. V & 0.010 \\
V vs. VI & 0.001 \\
\hline
\end{tabular}

APC: Annual pharmacy cost

Table 8: Comparison of ASC in different groups

\begin{tabular}{ll}
\hline Groups & p value \\
\hline I vs. III & 0.004 \\
I vs. IV & $<0.0001$ \\
I vs. VI & $<0.0001$ \\
II vs. VI & $<0.0001$ \\
III vs. VI & $<0.0001$ \\
V vs. VI & $<0.0001$ \\
\hline
\end{tabular}

ASC: Annual surgical cost

DNeu (Group V) had minimum expenses among the complications of diabetes, but AMC, ALC, APC, ACC, AHBC, and ASC of this group were $2,1.6,2.6,1.9,1.1$, and 1.9 times higher, respectively, than those in uncomplicated group.

As expected, the group without any complications, had reduced cost pattern for all the parameters, which is evident that high costs for diabetes care are not just due to the disease but due to its associated complications. Our reports are supported by a recent study by Leelavathi

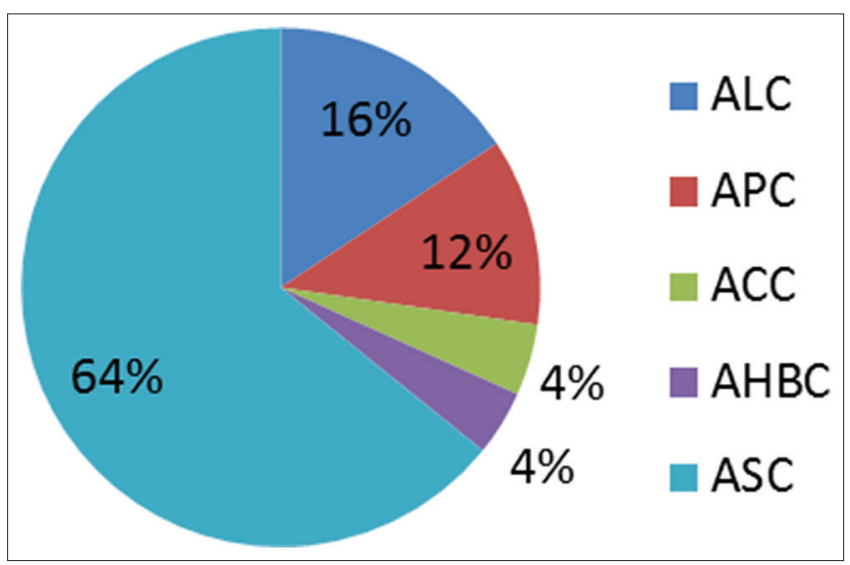

Fig. 6: Percentage of various costs in diabetic neuropathy

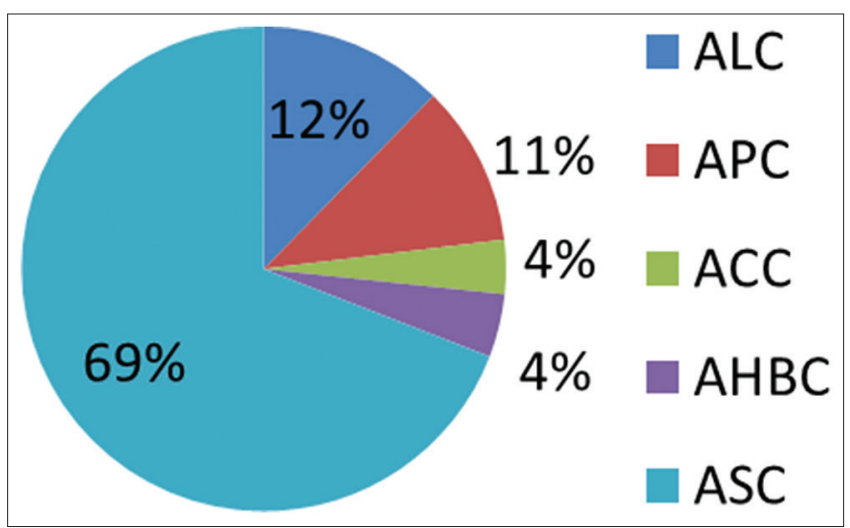

Fig. 7: Percentage of various costs in ischemic heart disease

et al. carried out in the same geographical area [28]. According to the study, average cost per diabetic patients without complications is Rs. 917.73 compared to the diabetic patients with complications Rs. 1448.51 per month. Annual cost of medication was found to be 1.6 times higher for diabetes with complication compared to those without complications. Cost-of-illness (COI) for DM with complication was reported to be 1.4 times higher than those without complications. Those patients who undergo dialysis in addition to the complications spend 7.3 times higher than those without complications. Patients who undergo cardiology intervention along with complications spend 7.4 times higher than patients who do not have complications. It also reports that hospitalization charge was 1.2 times higher for DM with complications. As per this study, cost per DM patient on dialysis (usually 2 times per week) is Rs. 97,920.00 per annum. Cost per diabetic patient undergoing cardiac intervention is Rs. 72,120.00 per intervention. It showed that annual cost of treatment for those who were on dialysis was 6.8 times higher and annual cost of treatment for cardiac intervention 
Table 9: Comparison of ACC in different groups

\begin{tabular}{ll}
\hline Groups & p value \\
\hline I vs. VI & $<0.0001$ \\
V vs. VI & 0.002 \\
\hline ACC: Annual consultation cost &
\end{tabular}

Table 10: Comparison of AHBC in different groups

\begin{tabular}{ll}
\hline Groups & p value \\
\hline I vs. VI & $<0.0001$ \\
II vs. VI & 0.034 \\
V vs. VI & 0.001 \\
\hline AHBC. Annual hospital bed costs
\end{tabular}

was 5 times higher than patients who did not have any intervention. Moreover, there may not be much difference in the cost of investigations, consultation cost, transportation, and indirect cost involved in diabetic care. They found that total COI for diabetic care without any complication was Rs. 22,456.97/- per patient per annum. Median of total COI for diabetic care with complication was Rs. 30,634.45/- per patient per annum, it was 1.4 times higher, median of COI for diabetic care with complication plus dialysis was Rs. $164,211.40 /$ - per patient per annum, it is 7.3 times higher and the median COI for diabetic care with complication plus cardiac intervention was Rs. 166,785.85/- per patient per annum which is 7.4 times higher and statistically significant difference observed between these groups. A similar study conducted by Metgud showed that cost of outpatient care for diabetic patient with chronic renal failure (CRF) requiring dialysis was 15 times higher than the cost of outpatient care for a diabetic patient without CRF (excluding dialysis cost) [29].

Compared to our study, costs mentioned in the above study were more. We cannot arrive at any conclusion by comparing numbers, as the costs are different in different settings. Even though cost variations exist, in general, we can conclude that diabetes poses economic burden which is amplified several times when associated complications.

The studies have reported the cost of managing diabetic patients with or without microvascular and macrovascular complications. Patients with microvascular complications had higher the cost of management, and those with macrovasular complications had even higher cost of management. Difference in the cost and proportions in different studies may be due to the period of study, place, method of collecting the data, and economic values. However, all the studies have concluded that diabetes is a disease associated with significant economic burden and diabetes complication make it more expensive. It is not only a burden to the patient, his family but also to the nation.

Our results support well-established fact that complications get worsen with longer duration of diabetes. Our study is in accordance with a report by Leelavathi et al. [28]. According to this study, regarding the duration of diabetes in the study population, $60.8 \%$ diabetic patients in without complication group had $<5$ years of history of diabetes, whereas in diabetes with complication group, $64.6 \%$ of diabetic patients had above 5 years of history of disease.

The total expenditure correlated significantly with age and duration of diabetes. The expenditure involved in treating long-term complications was significantly associated with duration of diabetes and presence of complications in the current study.

The duration of stay in the hospital, number of visits made for postsurgical dressings, hospital charges, laboratory charges, and medical consultations are the factors which significantly contribute to the increased cost in DF. The duration of hospital stay which is substantially longer in patients with foot complications increase the cost. Such information on hospital stay days and costs may help to emphasize earlier intervention and prevention of complications of diabetes.

The cost of diabetes can be a major burden as the disease does not have cure, and its complications increase with increasing duration of the disease. This was seen in a study by Chandra et al., a positive correlation of increasing cost with duration of diabetes [30].

Factors such as education and socioeconomic condition of the patient do contribute the cost in case of diabetes. It has been documented that urban people spend more money on diabetes compared to rural counterpart not only due to better awareness but also due to greater affordability [31].

A study by Hussain et al. suggested that the requirement of resources could be minimized by better care, treatment, and understanding of the disease [32]. Anandayani et al. suggested that intensified glycemic control is important in reducing complications and also to improve the quality of life in diabetic patients [33].

\section{Limitations of the study}

There are a few limitations in our study design. It is important to note that the data collected is from medical college teaching hospitals and the generalizability of results may be limited to certain private healthcare centers, the projected cost estimates were mainly based on urban patients whose pattern of disease may be different compared to rural patients. We could not assess the indirect cost and the cost of care for structured and comprehensive assessment of disability in this study. Educational and other socioeconomic details of patients could not be accessed as it was a hospital based study.

\section{CONCLUSION}

DM is a disease with significant financial burden which imposes an economic burden. The total AMC is significantly higher in complicated diabetic patients as compared to those without complications. Diabetic patients with IHD had the highest expenses, followed by DN, DF, DR, and DNeu which was least expensive. Positive correlation between duration of diabetes and costincurred and negative correlation of glycemic control and cost incurred, suggest a need for strategies that aim at reducing the escalating cost burden by achieving targeted glycemic control, prompt and effective management of complications, and operationalize regular and early screening for complications. Awareness creation on primary and secondary prevention of diabetes and its complications is the need of the hour, alongside capacity strengthening of medical and paramedical professionals involved in diabetes care.

\section{ACKNOWLEDGMENTS}

Sincere thanks to Dr. Shivakumar Hiremath, Medical Superintendent, Justice K.S. Hegde hospital, Mangalore, for permitting collect data and Mrs. Meenakshi, Medical Records Officer, KSHEMA hospital and Mrs. Leena, MRD, for cooperation in accessing the data.

\section{AUTHORS' CONTRIBUTIONS}

The first author has designed the study, conducted the research, analyzed the statistics and prepared the manuscript while. The second author has reviewed the literature and performed proofreading of the manuscript.

\section{CONFLICTS OF INTEREST}

None.

\section{REFERENCES}

1. Diabetes: The Cost of Diabetes, Fact Sheet No. 236. World Health Organization; 2002. Available from: http://www.who.int/mediacentre/ factsheets/fs236/en/.

2. Shobhana R, Rao PR, Lavanya A, Williams R, Vijay V, Ramachandran A. Expenditure on health care incurred by diabetic subjects in a developing 
country? A study from southern India. Diabetes Res Clin Pract 2000;48:37-42.

3. Shobhana R, Rao PR, Lavanya A, Williams R, Padma C, Vijay V, et al. Costs incurred by families having Type 1 diabetes in a developing country - A study from Southern India. Diabetes Res Clin Pract 2002;55:45-8

4. Rao KD, Bhatnagar A, Murphy A. Socio-economic inequalities in the financing of cardiovascular and diabetes inpatient treatment in India. Indian J Med Res 2011;133:57-63.

5. Grover S, Avasthi A, Bhansali A, Chakrabarti S, Kulhara P. Cost of ambulatory care of diabetes mellitus: A study from north India. Postgrad Med J 2005;81:391-5.

6. Kumar A, Nagpal J, Bhartia A. Direct cost of ambulatory care of Type 2 diabetes in the middle and high income group populace of Delhi: The DEDICOM survey. J Assoc Physicians India 2008;56:667-74.

7. Ramachandran A, Ramachandran S, Snehalatha C, Augustine C, Murugesan N, Viswanathan V, et al. Increasing expenditure on health care incurred by diabetic subjects in a developing country: A study from India. Diabetes Care 2007;30:252-6.

8. Shivaprakash G, Nishith RS, Basu A, Pallavi S, Adhikari P, Gopalakrishna HN, et al. Dispensing patterns and cost of glucose lowering therapies in diabetes mellitus patients at a tertiary care hospital in Southern India. Drug Invent Today 2012;4:671-3.

9. Adiga S, Adiga U. Health care cost incurred by patients of diabetes mellitus in a tertiary care hospital setting in coastal Karnataka district. J Glob Pharm Technol 2010;2:8-12.

10. Kumpatla S, Kothandan H, Tharkar S, Vishwanathan V. The costs of treating long term diabetic complications in a developing country: A study from India. J Assoc Physicians India 2013;61:102-9.

11. Kuchake V, Kumbhar P, Dighore P, Patil P. Comparison of lipid profile pattern in obese and non-obese Type 2 diabetic patients and to study the prescription pattern of antidiabetic drugs. Int J Pharm Sci Rev Res 2010;4:53-8.

12. Joshi A, Mohan K, Grin G, Perin DM. Burden of healthcare utilization and out-of-pocket costs among individuals with NCDs in an Indian setting. J Community Health 2013;38:320-7.

13. Akari S, Mateti UV, Kunduru BR. Health-care cost of diabetes in South India: A cost of illness study. J Res Pharm Pract 2013;2:114-7.

14. Abdi AH, Churi S, Kumar YS. Study of drug utilization pattern of antihyperglycemic agents in a South Indian tertiary care teaching hospital. Indian J Pharmacol 2012;44:210-4.

15. Schlatter RP, Hirakata VN, Polanczyk CA. Estimating the direct costs of ischemic heart disease: Evidence from a teaching hospital in BRAZIL, a retrospective cohort study. BMC Cardiovascular Disorders 2017;17:180.

16. Jose JV, Jose M, Devi P, Satish R. Pharmacoeconomic evaluation of diabetic nephropathic patients attending nephrology department in a tertiary care hospital. J Postgrad Med 2017;63:24-8.
17. Khanna U. The economics of dialysis in India. Indian $\mathrm{J}$ Nephrol 2009;19:1-4

18. Satyavani K, Kothandan H, Jayaraman M, Viswanathan V. Direct costs associated with chronic kidney disease among Type 2 diabetic patients in India. Indian J Nephrol 2014;24:141-7.

19. O'Brien JA, Patrick AR, Caro JJ. Cost of managing complications resulting from Type 2 diabetes mellitus in Canada. BMC Health Serv Res 2003;3:7.

20. Karlberg I, Nyberg G. Cost-effectiveness studies of renal transplantation. Int J Technol Assess Health Care 1995;11:611-22.

21. Olivera EM, Duhalde EP, Gagliardino JJ. Costs of temporary and permanent disability induced by diabetes. Diabetes Care 1991;14:593-6.

22. Zoungas S, de Galan BE, Ninomiya T, Grobbee D, Hamet P, Heller S, et al. Combined effects of routine blood pressure lowering and intensive glucose control on macrovascular and microvascular outcomes in patients with Type 2 diabetes: New results from the advance trial. Diabetes Care 2009;32:2068-74

23. Ramachandran R, Jha V. Kidney transplantation is associated with catastrophic out of pocket expenditure in India. PLoS One 2013;8:e67812.

24. Reiber GE, Lipsky BA, Gibbons GW. The burden of diabetic foot ulcers. Am J Surg 1998;176:S5-10.

25. Lobmann R. Diabetic foot syndrome. Internist (Berl) 2011;52:539-48.

26. Bakker K, Riley PH. The year of the diabetic foot. Diabetes Voice 2005;50:11-4.

27. International Working Group on the Diabetic Foot: International Diabetes Federation Report: International Diabetes Federation. Updated: 2000. Available from: http://www.idf.org/webdata/docs/ Diabetes_and_foot.pdf.

28. Leelavathi $\overline{D A}$, Rau NR, Udupa N, Rajan MS, Vijayanarayana K. Assessment of cost of illness for diabetic patients in South Indian tertiary care hospital. J Pharm Bioallied Sci 2016;8:314-20.

29. Bhaskaran VP, Rao NR, Satyashankar, Acharya RR, Metgud CS, Koshy T. A Study of direct costs incurred by Type 2 diabetes mellitus patients for their treatment at a large tertiary care hospital in Karnataka, India. J Acad Hosp Adm 2003;15:1-5.

30. Chandra P, Gogate B, Gogate P, Thite N, Mutha A, Walimbe A. Economic burden of diabetes in urban Indians. Open Ophthalmol J 2014;8:91-4

31. Ramachandran A, Snehalata C, Latha E, Vijay V, Vishwanathan M. Rising prevalence of NIDDM in urban population in India. Dialectologia 1997;40:232-7.

32. Hussain M, Baqir S, Naqvi S, Khan MA, Rizwi M, Alam S, et al. Direct cost of treatment of diabetes mellitus Type 2 in Pakistan. Int J Pharm Pharm Sci 2014;6:261-4.

33. Anandayani TM, Ibrahim MI, Adie AH. The association of diabetes related factor and quality of life in Type 2 diabetes diabetes mellitus. Int J Pharm Pharm Sci 2010;2:139-45. 